\title{
Introduction to the Special Theme on Re-Imagining the $M$ in STEM: Mathematical Actions for Innovative, Resilient and Culturally Rich Communities
}

\author{
Cynthia Nicol (D) Kathleen Nolan (1) \\ Florence Glanfield • Krista Francis $\mathbb{D}$ \\ Published online: 15 June 2020 \\ (C) Ontario Institute for Studies in Education (OISE) 2020
}

In 2018, a report by the United Nations Intergovernmental Panel on Climate Change (IPCC) announced the global average temperature is currently $1{ }^{\circ} \mathrm{C}$ warmer now than pre-industrial levels (IPCC, 2018). The report referred to this warming as human-induced, stating human influence has "become a principal agent of change on the planet" (IPCC, 2018, p. 53). Evidence of this change is being felt worldwide with 2018 witnessing life-threatening weather patterns in the USA and South-east Asia, extreme drought in South Africa and unexpected boreal forest fires in the Arctic. Such calls announcing the earth's environmental ecological crises are worldwide and difficult to ignore. How did we get to this situation? Some argue that this ecological crisis stems from a particular view of being in the world, a way of being that privileges individualism, consumerism as progress, and use of non-renewable energy resources as human rights (Barwell, 2018; Bowers, 2017). Acknowledging the crisis leads to questions on the role education can and should play in responding to these ecological challenges. More specifically, we ask how mathematics education, mathematics teacher education, and STEM and STEM education (Science, Technology, Engineering and Mathematics) might contribute to understanding and responding. How can the mathematics of STEM and STEM education be re-imagined to contribute to more sustainable practices, more innovative, resilient and culturally rich communities? This Special Theme of CJSMTE explores these questions across national and international contexts, rethinking the role of STEM and STEM education to consider other ways of relating to each other, mathematics and communities.

\author{
C. Nicol $(\bowtie)$ \\ University of British Columbia, 2125 Main Mall, Vancouver, B.C. V6T 1Z4, Canada \\ e-mail: cynthia.nicol@ubc.ca \\ K. Nolan \\ Faculty of Education, University of Regina, 3737 Wascana Parkway, Regina, Saskatchewan S4S 0A2, Canada \\ e-mail: kathy.nolan@uregina.ca \\ F. Glanfield \\ Vice-Provost Indigenous (Programming and Research), University of Alberta, 2-40 South Academic Building, Edmonton, AB \\ T6G 2G7, Canada \\ e-mail: glanfiel@ualberta.ca \\ K. Francis \\ Werklund School of Education, University of Calgary, 2500 University Drive N.W, Calgary, Alberta T2N 1N4, Canada \\ e-mail: kfrancis@ucalgary.ca
}


Emphases on STEM and STEM education spring from several sources, including international comparative testing, shortages of STEM workers and need for technological innovation in competitive international business markets (Atkinson \& Mayo, 2010; European Parliament, 2015; Gonzalez \& Kuenzi, 2012; Government of Canada, 2018; Royal Society Science Policy Centre, 2014). Many of these concerns are framed in a highly competitive, globalized socioeconomic context. Government and policy reports worldwide argue that a changing global economy in a post-industrial era requires a workforce that is STEM literate (European Parliament, 2015; Government of Canada, 2018; Royal Society Science Policy Centre, 2014). In the United States, for example, the National Science and Technology Council's Committee on STEM education (2018) refers to STEM as critical in order for the United States to be "the global leader in STEM literacy, innovation, and employment" (p. v) and "to be able to compete globally for scientific and technological talent” (p. 1). Similarly, in the UK, the Industrial Strategy White Paper (UK HM Government, 2017) examined approaches to increase economic productivity and earning power of people calling for improved STEM education as a key intervention. China recognizes that even with its large population, it "is facing the challenge of serious shortage of innovative talents" in STEM (Wang et al., 2018, p. para 3). Like other countries, Australia's Office of the Chief Scientist outlines the need for a specialized workforce with STEM skills stating that Australia's future "is a future with STEM" (Office of the Chief Scientist, 2016, p. iii).

This Special Theme takes a different perspective on STEM and STEM education. Moving beyond, but not ignoring, concerns for curriculum that builds strong economies, this Special Theme addresses the role of mathematics ("the M in STEM"), sustainable development, equity, Indigeneity and underserved rural communities in STEM education. STEM education in Canada offers a different vision of STEM learning for graduates in its report Canada 2067 (Parkin, 2018). Unlike other country national reports, this paper states "the goal of Canada 2067 is not to steer more students into STEM fields of study and careers" (Parkin, 2018 , p. 6). Instead, the report emphasizes the need of STEM skills for all students, all careers and all citizens and focuses on STEM education as providing contexts to learn critical thinking, problem solving and cross-cultural understanding. Canada 2067 considers these skills as key for engaging students in complex world issues such as creating access to quality education for all, ending world hunger and addressing climate change. In fact, the Canada 2067 STEM Learning Framework recognizes the need for ongoing teacher professional learning and support for increasing teacher confidence to incorporate other worldviews and cultures, particularly Indigenous ways of knowing and perspectives into STEM teaching and learning (Parkin, 2018). From this perspective, STEM education is not about delivering more math and science for students; it is about a dramatic rethinking of how students can be engaged in and contribute to solving some of the pressing issues of our time (Davis et al., 2019).

Offering critiques of STEM education, Wolfmeyer et al. (2017), Kumashiro (2018) and Zeidler (2016) advocate for an education beyond proficiency in STEM disciplines. Arguing against a STEM-centric view of education, Zeidler (2016) defines a deficit model of STEM as one focused on education that neglects to also consider the global perspectives contextualizing the disciplines. Instead, Zeidler (2016) advocates for a type of STEM education where:

it is fundamentally important for any student to be able to frame any STEM topic in a personal, thoughtful and meaningful context so as to allow for open inquiry, discourse, and evidence-based reasoning (p. 12).

Kumashiro (2018) and Wolfmeyer et al. (2017) call us to be critical of the mathematics and science of STEM education under current calls for improving economic revitalization and global competitiveness. Kumashiro (2018) reminds us that mathematics "plays no less a colonizing role than any other discipline" (p. 5) suggesting that mathematics can perpetuate injustices while at the same time be a tool for addressing complex social, ecological and cultural issues. As such, STEM education can actually be a place to bring mathematics and science education in critical dialogue across disciplines, across curriculum borders and 
across issues. This means that dialogues between STEM education, mathematics education and critical education are crucial for strengthening democracy and can, as Kumashiro (2018) suggests, "trouble the very things being taught" (p. 6).

In troubling education itself, Bowers (2017) contends we might begin by working "within a paradigm that does not colonize other cultures" (p. 54). Education, however, is a colonizing practice. Canada's Truth and Reconciliation Commission of Canada (TRC) (2015a) reports of past, present and future relationships between Indigenous and non-Indigenous peoples, between colonizers and colonized and between an education designed to segregate and forcibly assimilate Indigenous children into mainstream Canada and an education rooted in relationships to the Land. The history of residential schools in Canada is complex and ongoing, with the last school closing in the province of Saskatchewan in 1996. These schools, funded by the Canadian government and run by Canada's churches, removed children from their families and communities in a process of cultural domination leading to intergenerational loss of language, traditions and cultural practices. School survivors reported being targets of severe emotional harm and traumatic abuse by school administrators and teachers (TRC, 2015a). Disturbingly, an estimated 6,000 children died in residential schools "all under the pretense of receiving an education" (Talaga, 2018, p. 65). The effects of residential schools in Canada are profound. "Education is what got us into this mess," states Justice Murray Sinclair, then chair of the TRC, "but education is the key to reconciliation" (Watters, 2015).

Reconciliation, or what Indigenous scholar Styres (2017) refers to as healing, is a complex process. On the one hand, reconciliation invites non-Indigenous Canadians, settlers and newcomers to become part of Canada's history with Indigenous peoples, to understand historical colonizing processes and policy making and to work beyond feelings of denial and guilt toward critical decolonizing practices, which include renegotiating identities and examining implicit biases (Cote-Meek, 2014; Regan, 2010). On the other hand, reconciliation involves Indigenous peoples in healing relationships to ceremony, language and culture, toward "(re)centering the principles, philosophies, and ontologies of Land" (Styres, 2017, p. 74) for sovereignty and self-government (Tuck \& Yang, 2018).

For Indigenous scholar Alfred (2009), however, the process of reconciliation for Canadians is morally flawed as it relies on "a false notion of moral equivalency" (p. 51) between Indigenous and non-Indigenous peoples. Alfred (2009) argues that reconciliation requires Indigenous peoples to fit into the colonial legacy without benefit of programs that will make substantive differences in their lives, while for non-Indigenous people, reconciliation is nonthreatening, requiring only a "trite statement of regret and ceasing of the practice of the most open forms of racism" (Alfred, 2009, p. 152). The barrier to reconciliation, states Alfred (2009), rests mainly on the non-Indigenous majority "and their willful denial of historical reality [that] detract[s] from any possibility of meaningful discussion on true reconciliation" (p. 152). Canada's TRC report and Calls to Action respond to Alfred's (2009) concerns by opening-up possibilities for meaningful discussions and action toward reconciliation.

Formal educational institutions across Canada are responding to the TRC's recommendations and 94 Calls to Action (TRC, 2015b) for reconciliation. Many universities across Canada require an Indigenous education course to be completed by all teacher education students, and some universities require such a course for all undergraduate students. Provincial elementary and high school curriculum, such as that in British Columbia and Ontario, require integrating Indigenous knowledges and ways of being across the curriculum in all subject areas. Although these educational requirements are in place across many institutions, decentering colonial social structures and relations of power continues to be challenging. That is, the fact that education is connected to colonizing institutions like universities and schools makes any efforts to reconcile difficult and complex. This is particularly so in the field of mathematics education, where mathematics is often seen as a decontextualized acultural discipline. Bishop (1990) actually accuses mathematics of being "one of the most powerful weapons in the imposition of Western culture" (p. 51) calling it "a secret weapon of cultural imperialism" (p. 51).

This Special Theme presents a collection of studies and inquiries that respectfully takes up building and centering relationships with communities, toward decolonizing educational practices - particularly the M in 
STEM - and to re-imagining a more holistic engagement with human and natural environments. The papers in this Theme work within and beyond STEM fields to individually and collectively examine processes of decolonizing practices of mathematics education; to re-imagine the M in STEM; and to re-imagine STEM so that youth, educators, Elders and communities can participate in creating and sustaining innovative, resilient and culturally rich communities. The papers provide examples of awakening, what Shaughnessy (2013) calls, the "silent M in STEM" (p. 324) through compelling projects located in contexts not typically considered in STEM and STEM education research agendas. While there are many intersections and overlapping interests among the six papers in this Special Theme, all seek to address, in messy, complex and tension-fraught ways, what is involved in (re)imagining the M in STEM.

We begin with Nicol et al. (2020), examining their own experiences as mathematics teacher educators toward re-imagining the M in STEM. In their paper "Teacher Educator Professional Learning with/in place: Storying the Work of Decolonizing Mathematics Education within a Colonial Structure," the authors explore their collective diverse experiences to increase their awareness of colonizing practices. Drawing upon Clandinin's narrative methodology of living, telling, re-telling and re-living, the paper examines ways of being and relating in contexts including a learning garden for teacher candidates, a classroom-based course on culturally responsive education for teachers and robotic lessons for Indigenous youth in a remote rural community. Tensions are shared and new possibilities explored as Nicol et al. (2020) offer their "collaborative journey[s] with an invitation to other[s] to re-live mathematics learning together, to ease and heal the scars on the land, and ourselves, where jagged worldviews collide". As with Khan's (2020) paper, the authors explore the M in STEM for "re-imagining relationships with mathematics, place, community and education".

Moving from mathematics teacher education to undergraduate mathematics instruction, our second paper highlights the experiences of mathematicians seeking to improve the experiences of non-STEM undergraduate students. Leung et al. (2020) in "Re-imagining Authentic Mathematical Experiences for nonSTEM Majors" each describe a messy authentic task that engaged their students' interests and prior experiences. This paper discusses tasks that include graphing incarceration rates to understand linear, quadratic and exponential relations; counting tiles in starblankets of increasing sizes to understand quadratic sequences; and providing time for students to extrapolate radiocarbon dating to understand exponential decay of remains of fish-eating prehistoric humans. The authors highlight the challenge of bringing authentic messy tasks into university mathematics classrooms and the need for scaffolding non-STEM students' learning. Noting that this kind of teaching can be uncomfortable for both students and instructors, the authors confirm the value of supportive professional communities to share and question ideas. They conclude citing the need for "continued innovation in the university mathematics classroom" so that both STEM and non-STEM majors build strong positive relationships with mathematics.

Yaro et al. (2020) in "Situated Perspectives on Creating Mathematics Tasks for Peace and Sustainability" discuss authentic mathematics tasks from an international perspective. In this third Special Theme paper, the authors reflect on their experiences teaching nationally and internationally, expressing the tensions between globalized colonization and attention to local contexts for engaging in authentic meaningful mathematics tasks. Yaro and colleagues explore how peace, sustainability and local issues can inform traditional science and mathematics teaching. Their challenges for implementing such curriculum include the conservative force of textbooks, the dominant discourse of technoscientificity, colonization and insufficient time. The authors draw on an example of money exchange in Ghana as a localized, contextualized and authentic task for reimagining the $\mathrm{M}$ in STEM from an interdisciplinary perspective.

While these papers by Yaro et al. (2020) along with Nicol et al. (2020) highlight the need for mathematics education to increase awareness of colonizing practices with/in place and amid issues of highly contextualized tensions, our next two papers engage ecological perspectives toward an intentional exploration of alternative meanings of/for STEM and its M. Steven Khan (2020) in "After the M in STEM: Towards Mathematics for Multispecies Flourishing" takes up the task of re-imagining the M in STEM by 
drawing upon philosopher and novelist Sylvia Wynter's cultural critique of what it means to be human. Khan plays with various conceptions of the M's in STEM (M is for Man, for After Man, for Multispecies, for Music). Drawing upon Wynter's project to reunite the human and the ecological, Khan skillfully and creatively explores "After the M in STEM" to redefine being human toward multispecies flourishing and freedom. This paper draws our attention to how mathematics in STEM and STEM education have knowledge structures that are both created and perpetuated in logics, such as plantation logics, economics and colonialism. Challenging discourses that call upon STEM and STEM education to address the world's current problems, Khan argues the need for actions, including alternate conceptions of temporality, that instead allow "for flourishing not only for ourselves as humans but for all our relations". Khan draws upon his own teaching experiences to offer examples for how mathematics and mathematics education can be places for re-imagining and re-connecting with kin and land, places where community, humans, nonhumans and surroundings co-exist and flourish.

In a similar manner, Glanfield et al. (2020) in their paper "Living Landscapes, Archi-text-ures, and Landguaging Algo-rhythms" re-imagine STEM from indigenous and ecological perspectives. The paper considers cultural forms of knowing, those forms deeply connected to the natural environment, to explore alternative meanings of STEM and identify possibilities for STEM if rooted within indigenous and ecological perspectives. The authors invite the reader to play with the ideas of living landscapes, topography, architecture and algo-rhythms alongside the architectural activities of Indigenous peoples to question taken for granted meanings of STEM and imagine STEM through forms of knowing deeply connect to the natural environment.

The team of Wiseman et al. (2020) continue this thread of exploring alternative meanings of STEM. They share experiences of non-Indigenous women working in relationship with Indigenous people and communities, toward "a commitment to create learning opportunities where Indigenous and non-Indigenous ways might circulate together". In their paper "Whole-some Artifacts: (STEM) Teaching and Learning Emerging from and Contributing to Community", the team shares work from three different projects in three different communities, braiding together "stories of STEM and community to consider how STEM might both emerge from and contribute back to community". While the authors express reluctance to use the term STEM to describe the work they do in their various contexts and communities, they propose a way to look at the $\mathrm{M}$ in STEM through projects and sites where mathematics arose more organically and where STEM is experienced "as a living, whole-some artifact of teaching and learning instead of disciplining structures imposed on teaching and learning".

Each of the papers in this Special Theme offers readers innovative and critical re-imaginings of the role of mathematics in STEM fields and STEM education. Two responses follow the papers: one by Yasmine Abtahi of Western Norway University of Applied Sciences and the other by Michael Marker and Shirley Anne Hardman of the University of British Columbia. Abtahi (2020) brings experience working in the fields of Indigenous and culturally responsive mathematics education across international contexts. Marker and Hardman (2020) provide perspectives from outside the field of mathematics education research drawing upon Marker's own experiences learning mathematics and their current experiences as Indigenous scholars and administrators. We leave readers with questions to consider as they engage with the collection of papers in this Special Theme and hope these questions linger beyond and call you back to this initial read:

- How have you experienced the M in STEM?

- Is there an obligation to re-imagine the M in STEM? Whose obligation is it? And for whom is the obligation directed?

- What role can/do Indigenous communities play in re-imagining pathways for STEM and STEM education?

- How can mathematics participate in re-imagining STEM and STEM education and to decolonizing educational practices? 
- How might/are you re-imagining the M in STEM?

\section{Compliance with Ethical Standards}

Conflict of Interest The authors declare that they have no conflict of interest.

\section{References}

Abtahi, Y. (2020). The "M" in STEM as a note of caution: Resilient to what and responsive to whose culture. Canadian Journal of Science, Mathematics, and Technology Education, 20(2). https://doi.org/10.1007/s42330-020-00093-8.

Alfred, T. (2009). Wasáse: Indigenous pathways of action and freedom. Toronto: University of Toronto Press.

Atkinson, R. \& Mayo, M. (2010). Refueling the U.S. innovation economy: Fresh approaches to Science, Technology, Engineering and Mathematics (STEM) Education. Information Technology and Innovation Foundation. Retrieved from https://itif.org/. Accessed 8 June 2020.

Barwell, R. (2018). Some thoughts on a mathematics education for environmental sustainability. In P. Ernest (Ed.) The philosophy of mathematics education today (pp. 145-160). New York: Springer.

Bishop, A. J. (1990). Western mathematics: The secret weapon of cultural imperialism. Race and Class, 32(2), 51-65.

Bowers, C. A. (2017). An ecojustice approach to educational reform in adult education. New Directions for Adult and Continuing Education, 2017(153), 53-64. https://doi.org/10.1002/ace.20221

Committee on STEM Education of the National Science and Technology Council (2018). Charting a course for success: America's strategy for STEM education. Retrieved from: https://www.whitehouse.gov/wp-content/uploads/2018/12 /STEM-Education-Strategic-Plan-2018.pdf. Accessed 8 June 2020.

Cote-Meek, S. (2014). Colonized classrooms: Racism, trauma and resistance in post-secondary education. Winnipeg: Fernwood Publishing.

Davis, B., Francis, K., \& Friesen, S. (2019). STEM education by design: Opening horizons of possibility. New York: Routledge.

European Parliament. (2015). Encouraging STEM studies for the labour market. http:/www.europarl.europa.eu/studies. Accessed 11 Mar 2019.

Glanfield, F., Thom, J., \& Ghostkeeper, E. (2020). Living landscapes, archi-text-ures, and land-guaging algo-rhythms. Canadian Journal of Science, Mathematics, and Technology Education, 20(2). https://doi.org/10.1007/s42330-020-00085-8.

Gonzalez, H., \& Kuenzi, J. (2012). Science, technology, engineering, and mathematics (STEM) education: A primer. Washington, DC: Library of Congress, Congressional Research Service. Retrieved from https://www.fas. $\mathrm{org} / \mathrm{sgp} / \mathrm{crs} / \mathrm{misc} / \mathrm{R} 42642 . p d f$. Accessed 8 June 2020.

Government of Canada. (2018). The Government of Canada and STEM. Retrieved from the Government of Canada website: https://www.ic.gc.ca/eic/site/013.nsf/eng/00014.html. Accessed 8 June 2020.

Intergovernmental Panel on Climate Change (2018). Special report on global warming of $1.5^{\circ} \mathrm{C}$. Retrieved from https://www. ipcc.ch/sr15/. Accessed 8 June 2020.

Khan, S. (2020). After the M in STEM: Towards mathematics for multispecies flourishing. Canadian Journal of Science, Mathematics, and Technology Education, 20(2). https://doi.org/10.1007/s42330-020-00089-4.

Kumashiro, K. (2018). Why and how STEM education matters in social justice movements. The Journal of Educational Foundations, 31(1-2), 3-5.

Leung, F., Radzimski, V., \& Doolittle, E. (2020). Re-imagining authentic mathematical experiences for non-STEM majors. Canadian Journal of Science, Mathematics, and Technology Education, 20(2). https://doi.org/10.1007/s42330-020-00084-9.

Marker, M. \& Hardman, S. (2020). The math people: Unwitting agents of empire who "like to stay in their lane" Canadian Journal of Science, Mathematics, and Technology Education, 20(2). https://doi.org/10.1007/s42330-020-00094-7.

Nicol, C., Gerofsky, S., Nolan, K., Francis, K., \& Fritzlan, A. (2020). Teacher educator professional learning with/in place: Storying the work of decolonizing mathematics education within a colonial structure. Canadian Journal of Science, Mathematics, and Technology Education, 20(2). https://doi.org/10.1007/s42330-020-00080-z.

Office of the Chief Scientist. (2016). Australia's STEM workforce: Science, technology, engineering and mathematics. Retrieved from https://www.chiefscientist.gov.au/2016/03/report-australias-stem-workforce/. Accessed 8 June 2020.

Parkin, A. (2018). Supporting education transformation in Canada. Retrieved from https://canada2067.ca/app/uploads/2018 /11/Canada-2067-Supporting-Education-Transformation-in-Canada_Final.pdf. Accessed 8 June 2020.

Regan, P. (2010). Unsettling the settler within: Indian residential schools, truth telling, and reconciliation in Canada. Vancouver: UBC Press. 
Royal Society Science Policy Centre (2014). Vision for science and mathematics education. Retrieved from https://royalsociety.org/topics-policy/projects/vision/. Accessed 8 June 2020.

Shaughnessy, J. M. (2013). Mathematics in a STEM context. Mathematics Teaching in the Middle School, 18(6), $324-324$. https://doi.org/10.5951/mathteacmiddscho.18.6.0324.

Styres, S. D. (2017). Pathways for remembering and recognizing indigenous thought in education: Philosophies of iethi'nihsténha ohwentsia'kékha (land). Toronto, Ontario: University of Toronto Press.

Talaga, T. (2018). All our relations: Finding the path forward. Toronto: House of Anansi Press.

Truth and Reconciliation Commission of Canada (TRC). (2015a). Honouring the truth, reconciling for the future summary of the final report of the Truth and Reconciliation Commission of Canada. Retrieved from https://www.trc.ca/. Accessed 8 June 2020.

Truth and Reconciliation Commission of Canada (TRC) (2015b). Truth and Reconciliation Commission of Canada: Calls to action. Government of Canada. Retrieved from http://nctr.ca/assets/reports/Calls_to_Action_English2.pdf. Accessed 8 June 2020.

Tuck, E., \& Yang, K. W. (2018). Introduction: Born under the rising sign of social justice. In E. Tuck \& K. W. Yang (Eds.) Toward what justice?: Describing diverse dreams of justice in education, (pp. 1-17). New York, NY: Routledge.

UK HM Government. (2017). Industrial strategy: Building a Britain fit for the future. Royal United Services Institution. White paper. Retrieved from https:/www.gov.uk/government/publications/industrial-strategy-building-a-britain-fit-for-thefuture. Accessed 8 June 2020.

Wang, X., Xu, W., Guo, L., Wang, X., Xu, W., \& Guo, L. (2018). The status quo and ways of STEAM education promoting China's future social sustainable development. Sustainability, 10(12), 4417. https://doi.org/10.3390/su10124417.

Watters, H. (2015). Truth and reconciliation chair urges Canada to adopt UN declaration on Indigenous Peoples. CBC News, June 01, Retrieved: https://www.cbc.ca/news/politics/truth-and-reconciliation-chair-urges-canada-to-adopt-undeclaration-on-indigenous-peoples-1.3096225. Accessed 8 June 2020.

Wiseman, D., Lunney Borden, L., Beatty, R., Jao, L., \& Carter, E. (2020). Whole-some artifacts: (STEM) teaching and learning emerging from and contributing to community. Canadian Journal of Science, Mathematics, and Technology Education, 20(2). https://doi.org/10.1007/s42330-020-00079-6.

Wolfmeyer, M., Lupinacci, J., \& Chesky, N. (2017). Critical education. Critical Education, 8(15), 37-39. https://doi. org/10.1007/978-1-137-42617-8_15.

Yaro, K., Amoah, E., \& Wagner, D. (2020). Situated perspectives on creating mathematics tasks for peace and sustainability. Canadian Journal of Science, Mathematics, and Technology Education, 20(2). https://doi.org/10.1007/s42330-02000083-w.

Zeidler, D. L. (2016). STEM education: A deficit framework for the twenty first century? A sociocultural socioscientific response. Cultural Studies of Science Education, 11(1), 11-26. https://doi.org/10.1007/s11422-014-9578-z.

Publisher's Note Springer Nature remains neutral with regard to jurisdictional claims in published maps and institutional affiliations. 